\title{
SOLIPSISMO LINGÜÍSTICO Y SOLIPSISMO TRASCENDENTAL: RUSSELL Y WITTGENSTEIN *
}

\author{
Álvaro Rodríguez Tirado \\ INSTITUTO DE INVESTIGACIONES FILOSÓFICAS \\ Universidad Nacional Autónoma de México
}

What has history to do with me? Mine is the first and only world! I want to report how I found the world (Notebooks).

1. El motivo principal de una doctrina solipsista cualquiera es, asumiendo la existencia de un ego o de su experiencia, restringir, bien (i) el tipo de cosas que existen (solipsismo ontológico o metafísico), o (ii) las verdades que podemos conocer o entender (solipsismo epistemológico o lingüístico), o (iii) las maneras de obtener el conocimiento de cosas o verdades cuya existencia o sentido está ya fuera de disputa (solipsismo metodológico).** A pesar de esta diversidad de formas que puede adoptar una doctrina o postura solipsista, existe un tema en torno al cual giran todas ellas, a saber, el funcionamiento lógico del pronombre de la primera persona.

- El presente trabajo fue leido ante la Asociación Mexicana de Filosofía, en un congreso celebrado por esta misma en la ciudad de Guanajuato en la semana del 7 al 14 de diciembre de 1981.

- A primera vista parecería extraño que el solipsismo trascendental no aparezca en esta lista, pero, como pretendo mostrar en el curso de este trabajo, no se trata de un tipo de doctrina diferente a las que ya he señalado en (i)-(iii), sino de una manera especifica de argumentar a favor de la verdad que encierra una doctrina solipsista -cualquiera que ésta sea. Esta manera de argumentar trata de las condiciones bajo las cuales algo, por ejemplo, nuestra experiencia de objetos espacio-temporales o el lenguaje mismo, es posible. Desde Kant, se ha denominado a este tipo de argumentos Argumentos Trascendentales. En la Critica de la Razón Pura, Kant escribió:

Llamo trascendental todo conocimiento que se ocupa, en general, no tanto de objetos como de nuestro modo de conocerlos, en cuanto éste debe ser posible a priori. (B25)

Nótese que las condiciones bajo las cuales se dice de algo que es posible son condiciones necesarias, no suficientes. La razón de que esto sea así es clara: si asumimos que tenemos experiencia de objetos espacio-temporales y consideramos la verdad de $p$ como una condición suficiente para la posibilidad de una tal experiencia, nada se seguiría por lo que toca a la verdad de la proposición $p$; mientras que si la conside- 
Hablar del funcionamiento lógico del pronombre de la primera persona parecería ser de interés tan sólo para el semántico o para el teórico de la referencia pero, en realidad, los problemas que subyacen a un tratamiento cabal de semejante expresión, son de una importancia filosófica general imposible de exagerar. Estos problemas podrían quedar encuadrados bajo el rubro de metafísica de la experiencia y, en esta área de la epistemología, el reto que nos propone el solipsismo figura de manera prominente. ¿Cómo podríamos convencer al solipsista de estar en lo incorrecto al afirmar que la única realidad es la realidad de su experiencia presente, o que su posición, tanto en la percepción como en la acción, siempre ha de ser una posición privilegiada, o que, en síntesis, él es el centro del mundo? $O$ zacaso la posición del solipsista es intrínseca y absolutamente incoherente? ¿Qué hacer, entonces, con lo que algún día dijera Russell respecto de que si uno estuviese dispuesto a creer que nada existe, excepto aquello de lo que se tiene experiencia directa, nada ni nadie podría probarnos que nos hemos equivocado ni tampoco parecería haber argumentos válidos en nuestra contra? Todas estas preguntas reclaman y merecen una respuesta. Pero no ahora. Quisiera, en cambio, mostrar simplemente una ruta, a mi parecer muy fructífera, de aproximarse a estos problemas. La ruta que propongo consiste en preguntarse por el modo de referir del pronombre 'yo' o, siguiendo la terminología de Frege, por el "modo de presentación" relevante para el caso de la auto-adscripción de predicados. Esta ruta que sugiero difícilmente puede estar del todo equivocada, ya que parecería confirmar la intuición que expresaba el propio Wittgenstein al escribir: "Estoy tratando de reducir todo el problema a nuestro no entender la función de la palabra 'yo' (y 'esto')." 1 Claro está que, argumentum ad verecundiam aparte, el veredicto final sobre lo apropiado de la ruta sólo podremos darlo una vez que hayamos llegado a nuestro destino.

La historia semántica del pronombre 'yo' es una historia tortuosa. Por una parte, hay quienes, sin cuestionar la función referencial del pronombre, han negado que tenga un sentido ( $\operatorname{sinn}$ ), y esto los ha llevado a concluir que el funcionamiento de dicho pronombre resulta imposible de explicar dentro del marco de una teoría fregeana del significado. ${ }^{2}$ Por otra parte, pueden encontrarse también filósofos que niegan que la función lógica del pronombre de la primera persona sea una función

ramos como una condición necesaria, podríamos afirmar su verdad. En otras palabras, argumentar ' $e$ y si $e$ entonces $p$, por tanto, $p$ ' es válido, pero argumentar ' $e$ y si $p$ entonces $e$, por tanto, $p^{\prime}$ no lo es.

1 Cf., "Notes for Lectures on 'Private Experience' and 'Sense-Data'", Philosophical Review, LXXVII (1968).

2 Tengo en mente, principalmente, a John Perry; vide 'Frege on Demonstratives', Philosophical Review LXXXVI, 4 (1977). 
referencial pero aceptan que dicho pronombre tenga un uso y, por tanto, un significado, en nuestro lenguaje. ${ }^{3}$ Pues bien, en lo que sigue voy a intentar explicar esta situación por demás curiosa. En realidad mi propósito en este trabajo es más limitado, ya que el verdadero objeto de mi análisis es tan sólo la tesis de que el pronombre 'yo' no es una expresión referencial. ¿Cuál es la relación — si es que hay alguna - entre dicha tesis y el problema filosófico del solipsismo?

Si mi interpretación es correcta, la tesis de que el pronombre 'yo' no es una expresión referencial es una consecuencia de lo que Wittgenstein sostuvo acerca del solipsismo en el Tractatus. Pero no es casual que lo dicho por Wittgenstein en esa obra pueda interpretarse como una reacción a las teorías de Russell sobre el ego y la auto-referencia, de manera que sólo estaremos en condiciones de entender la discusión a que nos invita el primero una vez que nos hayamos convencido de que entendemos las doctrinas, semánticas y epistemológicas, que propone el segundo.

La manera como voy a proceder es la siguiente: En $\$ 2$ examinaré y criticaré la teoría que Russell sostuvo en el año de 1912 sobre el ego y la auto-referencia, según la cual sólo puede conocerse al yo mediante una relación de conocimiento directo (acquaintance); en $\$ 3$ consideraré la posición de Russell al abandonar esta teoría y discutiré una objeción semántica preliminar a $(\$ 4)$ la crítica de Wittgenstein a la segunda teorfa de Russell sobre el yo y la auto-referencia, esto es, Ia teoría según la cual el yo sólo puede conocerse mediante descripción; en $\S 5$ argumentaré que la discusión de Wittgenstein sobre el solipsismo en el Tractatus sienta la base, como ya he dicho, para la doctrina que vino a sostener años después, a saber, que hay ciertos usos del pronombre 'yo' en los cuales su función lógica no es una función referencial.

2. Hace ya muchos años estaba de moda una teoría según la cual la función de un término singular era introducir a su referente en la proposición que resulta de la aserción de la oración en la que figura dicho término. La noción de proposición relevante aquí es la que David Kaplan ha denominado ${ }^{4}$ una proposición singular, esto es, una proposición que puede ser representada como un par ordenado de la forma

$$
<\mathrm{F}^{\mathrm{n}},\left\langle\mathrm{x}_{1}, \ldots, \mathrm{x}_{\mathrm{n}}>>\right.
$$

3 Cfr. E. Anscombe, "The First Person" en Mind and Language, The Wolfson College Lectures in Philosophy, ed. S. Guttenplan, Oxford University Press, London. Ver también los artículos de A. Kenny, R. Chisholm y $N$. Malcolm recogidos en Intention and Intentionality. Essays in Honour of E. Anscombe, The Harvester Press, Sussex, 1980.

4 En su artículo "How to Russell a Frege-Church", The Journal of Philosophy (1975). 
en donde $F^{n}$ es una función proposicional n-aria $y\left\langle x_{1}, \ldots, x_{n}\right\rangle$ una secuencia n-aria de individuos. Una proposición tal es verdadera en cualquier mundo posible si y sólo si la secuencia n-aria de individuos satisface la intensión $n$-aria en ese mundo. En otras palabras, la teoría nos dice que, si $t$ es un término singular y $\mathrm{S}(t)$ una oración en la cual figura dicho término, entonces la proposición que resulta de la aserción de la oración $\mathrm{S}(t)$ es una proposición singular que contiene, como uno de sus elementos, al referente de $t$ en esa oración, si es que hay alguno; de otra manera la emisión de la oración $S(t)$ no expresa ninguna proposición.

Russell fue notablemente uno de los precursores de esta teoría. Como es de todos sabido, Russell defendió una teoría realista del significado según la cual el significado de una palabra es la cosa misma que sirve a la vez como su referente. Hemos visto ya cómo, si una expresión para la cual esto es verdadero - un buen candidato sería, según Russell, el pronombre 'yo'- figura en una oración, entonces, esa cosa que es a la vez su significado viene a formar parte de la proposición que dicha oración expresa. En palabras de Russell esa cosa viene a ser un "constituyente de la proposición".

No tardó Russell en abandonar toda esperanza en la viabilidad de esta empresa pero, recientemente, el trabajo de Kripke, Putnam, Donnellan y otros ha hecho que muchos filósofos vuelvan a sentirse atraídos por ella. Sólo que ahora la denominan la "Nueva Teoría de la Referencia". ${ }^{5}$ Esta teoría, en mi opinión, está condenada al fracaso por una razón muy sencilla. Saber el significado de una oración y, por tanto, saber sus condiciones de verdad, no es otra cosa que saber el tipo de pensamiento expresable mediante su uso pero, desde esta perspectiva, la "nueva teoría de la referencia" resulta grotesca, ya que sostiene que el pensamiento expresado por una oración en la que figura un término singular es exactamente el mismo pensamiento que aquél expresado por cualquier oración que resulte de substituir el término singular que figura en la primera oración por cualquier otro término singular con el mismo referente. Pero hablar aquí del mismo pensamiento resulta inapropiado, ya que alguna persona podría saber que la proposición "Hesperus es un planeta" es una proposición verdadera e ignorar que la proposición "Phosphorus es un planeta" también lo es y, sin embargo, dado que Hesperus es Phosphorus, la nueva teoría de la referencia nos diría que ambas oraciones expresan el mismo pensamiento. El problema es obvio: si ambas oraciones expresasen el mismo pensamiento, resultaria ser un misterio el que una persona mínimamente racional adoptase actitudes epistémicas distintas ante la proposición singular en cuestión.

5 Véase por ejemplo la introducción de S. P. Schwartz a la colección de artículos 
Éste es un problema cuya solución sólo podrá encontrarse en una teoría del pensamiento en la mente de una persona que usa un término singular en un determinado contexto. Si los nombres y pronombres son o no, como diria Kripke, "designadores rígidos", si su comportamiento difiere del de las descripciones definidas al caer bajo el alcance de un operador modal, son problemas muy distintos. Por mi parte, pienso que estos problemas lógico-semánticos de los que Kripke se ocupó en su famoso artículo "Naming and Necessity", 6 pueden explicarse en el sentido de ofrecerles un fundamento filosófico, fundamento que deberá buscarse, como dije antes, en una teoría del pensamiento sobre individuos. Lo que subyace, pues, a una teoria de la referencia es, como ya he dicho en otra ocasión, ${ }^{7}$ una teoría de las actitudes proposicionales de re.

No es de dudarse que Russell estuviese consciente de los problemas a que he hecho mención y, así, vio desde sus inicios la necesidad de vincular su teoría realista del significado con la epistemología del entendimiento. Fue así como Russell postuló un principio que establece una restricción en nuestro entendimiento de los significados de distintas expresiones. Russell lo llamó el Principio del Conocimiento Directo (Principle of Acquaintance) y, en Los Problemas de la Filosofia, ${ }^{8}$ lo formuló de la siguiente manera:

Toda proposición que podamos entender debe estar compuesta en su totalidad por constituyentes de los cuales tenemos un conocimiento directo.

Ésta es la base de la doctrina denominada solipsismo lingüistico: su propósito es restringir o limitar las cosas que podemos entender ( $\$ 1$ ) mediante la relación de conocimiento directo. Si el efecto restrictivo que pretende es o no exitoso es algo que va a depender de si es posible identificar a aquéllo que sirve como el punto de referencia en base al cual se establece la restricción, a saber, el ego o el campo de objetos presentado ante su conciencia. Pero esto es adelantarnos a lo que va a venir. Por lo pronto interesa examinar la base de esta doctrina. Su examen deberá comenzar, pienso, con el análisis de la noción de conocimiento directo. Russell la denomina 'acquaintance' y la considera como la manera mediante la cual la mente aprehende las cosas, sean éstas las cosas que lleva como titulo Naming, Necessity \& Natural Kinds, Cornell University Press, Ithaca, 1977.

6 Originalmente publicado en Semantics for Natural Language (eds.) Davidson and Harman, Reidel Publishing Company, Holland, 1971.

7 Véase mi artículo "La Primera Persona: Una módica defensa de Frege" en Teorema, vol. IX/3-4 (1979).

\& La traducción al español de esta obra de Russell publicada en 1942 fue realizada por Joaquín Xirau; Labor, Barcelona, 1970. 
presentadas ante nuestra conciencia en la percepción o en algunos tipos de memoria o bien en la introspección. Ésta es la primera función que Russell asigna a la noción de conocimiento directo, pero no es la única. Russell piensa que esta noción también deberá explicarnos cómo es que la mente aprehende ciertas verdades acerca de las cosas. El problema es que estas dos funciones son incompatibles entre sí, de manera que nó hay nada que pueda satisfacerlas o que, simultáneamente, pueda desempeñarlas y, por tanto, la teoría de Russell debe abandonarse.

En esta etapa de su filosofía, Russell sostuvo que cada persona tiene un conocimiento directo de su propio yo o ego. Según él, cuando véo el sol tengo conocimiento directo, por una parte, del dato de los sentidos que representa al sol y, por otra, de aquello que ve este dato de los sentidos. Sólo si postulamos un conocimiento directo del yo - nos dice Russell - podemos saber o incluso entender la verdad "yo tengo un conocimiento directo de este dato de los sentidos". Así, el efecto de restringir su teoría realista del significado mediante el principio del conocimiento directo, es claro; dado que tengo conocimiento directo de $\mathrm{mi}$ yo o ego, me puedo referir a él mediante el uso del pronombre 'yo' y si entonces emito por ejemplo, la oración, 'Yo tengo un dolor', mi propio ego, siendo como es, 'según Russell, el significado del pronombre, viene a ser un constituyente de la proposición que expreso al emitir esa oración.

Comparemos brevemente lo que nos dice Russell y lo que sugiere el sentido común, que es, en mi opinión, la tesis correcta. Lo que sostiene el sentido común es que el pronombre 'yo' refiere a la persona que lo usa, un ente pensante y corpóreo que es a la vez el usuario del lenguaje. Russell, en cambio, piensa que la palabra 'yo' refiere a un ego, es decir, al sujeto mismo de la experiencia. Russell distingue a esta entidad de la persona, considerada ésta como un ente cuya existencia se extiende a través del tiempo. ${ }^{9} \mathrm{Si}$ asumimos que la persona es un ente material (corpóreo) Russell argumentaría que es imposible tener un conocimiento directo de ella y, por tanto, nos diría que es imposible que dicha entidad figurase como un constituyente de la proposición. Esto es una consecuencia de lo que Russell entiende por 'conocimiento directo', a saber, un tipo de conocimiento esencialmente simple y lógicamente independiente de cualquier conocimiento de verdades. Pero, ¿con qué derecho hablamos de conocimiento aquí? Cuando un sujeto, $S$, tiene conocimiento directo de un objeto, $O$, parecería saber en todos los casos una $\mathrm{u}$ otra verdad acerca del objeto, y esto por la sencilla razón de que, si hemos de hablar justificadamente de conocimiento, el sujeto debe al me-

9 Cfr. "On the Nature of Acquaintance", The Monist, 1914. Reimpreso en Logic \& Knowledge, ed. R. C. Marsh, Allen \& Unwin, London, 1956, p. 163. 
nos ser capaz de re-identificar al objeto en una ocasión futura cuando se presente ante él. En otras palabras, $S$ debe al menos saber qué tipo de objeto es $O$, y esto a pesar de que en muchos casos este conocimiento se manifieste tan sólo en su habilidad de reconocer a $O$ de nuevo sin que sea capaz de decirnos cómo lo hizo. Empero, Russell insistió en tratar al conocimiento directo como si fuese lógicamente independiente del conocimiento de verdades, esto es, como una relación extensional entre sujeto y objeto, de manera que, si un sujeto tiene conocimiento directo de un objeto, entonces podemos concluir que, necesariamente, hay algo de lo cual dicho sujeto tiene tal conocimiento.

Veamos ahora el caso de la introspección. Mediante esta facultad un sujeto está consciente de (la existencia de) sí mismo. Pensemos a la relación de conocimiento directo como el punto final al cual arribamos mediante un proceso de sustracción..$^{10}$ Podemos identificar la conciencia que trae aparejada la introspección con aquello que queda una vez que hayamos sustraído todo conocimiento de verdades que el sujeto tiene de sí mismo. Podríamos entonces llamar a esta conciencia 'conocimiento directo del yo o ego'. Preguntemos ahora cómo es que podemos hablar de conocimiento aqui. No podriamos contestar que la conciencia que acompaña a la introspección se constituirá en conocimiento sólo en el caso que el sujeto $S$ sea capaz de re-identificar a su ego en una ocasión futura puesto que, en este período de su filosofía, Russell trató al yo como si fuese un dato de los sentidos y, por lo tanto, como si gozase tan sólo de una existencia momentánea. Es precisamente esta noción de conocimiento directo (acquaintance) concebida como una fuente de conocimiento y significado y considerada como una relación simple, completa y capaz de existir con plena autosuficiencia, lo que empaña todo contraste entre su teoría de la auto-referencia y su explicación de la manera de referir de otras expresiones. Como veremos más adelante, éste es uno de los aspectos por el cual la teoría de Russell se hace vulnerable a las críticas que Wittgenstein le dirigió en el Tractatus.

Revisemos ahora la situación obtenida hasta aquí. Hemos visto que, cuando un sujeto tiene un conocimiento directo de su propio yo o ego mediante la introspección, está en posición de referir a él mediante el uso del pronombre 'yo'. Dada la extensionalidad de la relación de conocimiento directo, sabemos también que tiene que haber algo de lo cual el sujeto tiene conocimiento directo $y$, de acuerdo a la teoría realista del significado de Russell, dicha entidad ha de servir como el signifi-

10 Sugerencia que he tomado de D. Pears. Véase su artículo "The Function of Acquaintance in Russell's Philosophy" en Synthese, vol. 46, $\mathrm{n}^{\circ} 2$, (1981). Aprovecho esta ocasión para agradecer al profesor Pears la paciencia sin límites que ha mostrado en la lectura y evaluación crítica de éste y otros trabajos. 
cado del pronombre 'yo'. Así, cuando el sujeto emite la oración "Yo tengo conocimiento directo de este dato de los sentidos", el yo viene a ser un constituyente de la proposición que esta oración expresa.

Es importante notar que ésta es la vieja noción de proposición singular que resulta totalmente inútil para poder dar cuenta de la organización funcional de una persona, I.os pensamientos, deseos, creencias, intenciones, etc., de una persona cualquiera forman un sistema con una organización funcional característica de él y es esto lo que nos permite o, mejor dicho, nos obliga a hablar de nuestros estados mentales como poseyendo un rol funcional tanto en la producción de la conducta como en el procesamiento de la información sensorial. Llamemos a este requisito que toda teoría sobre nuestros estados mentales debiera satisfacer, el requisito del rol funcional.

Ahora bien, es claro que, en la teoría de Russell, la relación de conocimiento directo media la referencia de un sujeto a sí mismo, de la misma manera que media también la referencia a los particulares que se presentan ante nuestra conciencia en la percepción y en algunos tipos de memoria. Dicho esto, es obvio que, dada la definición original de conocimiento directo que Russell nos ofreció, dicha relación no puede satisfacer el requisito del rol funcional, ya que nada nos dice acerca de la manera como el sujeto identifica al objeto del cual tiene un conocimiento directo.

Esto significa que, o bien somos capaces de suplementar la teoría de Russell, o bien resulta imposible entender cómo es que la relación de conocimiento directo puede desempeñar la segunda función, esto es, ser la fuente del conocimiento de verdades básicas sobre objetos particulares. Russell vio el problema y pensó que la solución se encontraba en permitir que el sujeto tuviese un conocimiento directo del dato de los sentidos complejo, a-en-la-relación-R-con-b, por ejemplo, el dato de los sentidos compuesto por una mancha roja a la izquierda de una mancha azul en el campo visual de $S$. Russell parecía haber pensado que si el sujeto atiende a este dato $\mathrm{y}$, sin apelar a ningún otro input -excepción hecha, claro está, de lo que le brinda la relación extensional de conocimiento directo- lo analiza distinguiendo sus tres componentes, estaría en una posición de formular el juicio de que $a$ se encuentra en la relación $R$ con $b$ y juzgaría que esto es así sin que exista la posibilidad de cometer un error. Pero los pensamientos y creencias que el sujeto adquiere de esta manera no pueden jugar el papel que nosotros les asignamos en la producción de la conducta y en el procesamiento de la información sensorial; estos pensamientos no podrían, en otras palabras, satisfacer el requisito del rol funcional a que me referí arriba. Russell apela aquí, una vez más, a la relación de conocimiento directo como 
una especie de conocimiento de cosas que se concibe como algo simple, autosuficiente, que tiene la ventaja de excluir toda posibilidad de error y puede ser así considerada como una base adecuada para el tipo de conocimiento más puro y cierto que Russell buscaba: un tipo de conocimiento que dependía en su totalidad del solo contacto con la cosa conocida, lo meramente dado, lo cual excluía cualquier reacción a lo que nos llega por los sentidos o, como en el caso del ego, se nos presenta en la introspección.

Dije antes que Russell trató de salvar esta dificultad considerando a la percepción del complejo a-en-la-relación-R-con-b como si fuese ella misma un caso de conocimiento directo. Esto daría a Russell lo que él quiere sólo si Russell permitiese que el sujeto identifique al menos uno de los tres componentes de manera que al hacerlo así el sujeto mostrase la aprehensión de alguna verdad acerca del objeto. Pero esto, como es obvio, entra en conflicto con el requisito que el mismo Russell impone de que, para que el sujeto llegue al juicio de que $a$ está de hecho relacionado con $b$, el sujeto no debe apelar a ninguna otra cosa salvo lo que le ofrezca la relación extensional de conocimiento directo.

La teoría de Russell no tiene manera de escapar a este dilema y hay otras dificultades de no menos importancia. Recordemos que, de acuerdo a Russell, sólo podemos conocer y entender la verdad que expresa la oración "Yo veo brillar el sol" si suponemos que tenemos conocimiento directo de aquello a lo que nos referimos con la palabra 'yo'. Esto sugiere que al analizar el juicio tenemos que separar los siguientes componentes: 'el sol', '(la relación o propiedad de) brillar', 'mi yo o ego', toda vez que, cuando tengo conocimiento directo de mi ver el sol, el hecho total del cual tengo conocimiento directo es 'Ego-en-conocimiento-directo-del-dato-de-los-sentidos'. Pero si esto ha de ser así no sólo tenemos una tensión en el sistema de Russell sino una inconsistencia evidente.Veamos.

Russell piensa que el error puede infiltrarse en lo que él llama el proceso de derivación de la percepción al juicio. Pero, dado que Russell acepta el conocimiento directo del yo o ego, nada parecería impedir que el error se infiltrase también en el proceso de derivar un juicio introspectivo acerca del yo o ego y, claramente, esto es un absurdo. El absurdo se origina por la manera como Russell concibe mi conocimiento de que (yo) estoy percibiendo un dato de los sentidos; esto es, Russell concibe a este tipo de (auto-)conocimiento como si fuese idéntico al caso en el que yo me entero de que otra persona, digamos Juan, ve un árbol, y esto, como era natural, lo lleva a sostener un sinsentido. Si para poder formular un juicio en el que reporto mi confrontación con algún dato de los sentidos visual es necesario 'percibir' un yo y un dato de los sentidos y, una vez realizado esto, observar que el yo percibe el dato en 
cuestión, entonces debería ser posible también, no sólo el percibir que el yo no percibe el dato de los sentidos sino, además y de mayor importancia para el tema que nos ocupa, debería ser posible también que yo percibiese un yo y observara que ese yo o ego no es mi propio ego.

$\mathrm{La}$ inconsistencia que acabo de describir me parece suficiente para rechazar la teoría de Rüssell $y$, como veremos más adelante, dicha inconsistencia es uno de los ejes sobre los cuales Wittgenstein hace girar todas sus críticas. Por ahora quisiera simplemente enfatizar que la manera que Russell escogería para bloquear esta crítica - la crítica, recordemos, consistente en mostrar que en su teoría existe la posibilidad de cometer un error por lo que toca al pensamiento sobre el yo del cual tenemos un conocimiento directo- va mano a mano con su concepción cartesiana de la relación de conocimiento directo (acquaintance), es de. cir, una relación epistemológicamente simple y autosuficiente susceptible de brindarnos el conocimiento más puro y cierto. Postular que existe un conocimiento directo del yo como Russell lo entiende, trae aparejada la idea de que el conocimiento obtenido de esta manera depende en su totalidad del mero contacto con la cosa que se presenta ante nuestra conciencia en la introspección, con algo que es meramente dado. Pero hemos visto ya que el aceptar esta doctrina es privar a su tesis del conocimiento directo del yo de toda relevancia epistemológica. Si el conocimiento directo del yo le da a Russell lo que él buscaba, entonces, no hay nada sobre lo cual podamos cometer un error, pero, de igual manera, no hay nada sobre lo cual podamos estar en lo correcto. Éste es el precio que Russell debería pagar por considerar a la relación de conocimiento directo como la primera piedra sobre la cual el resto de nuestro conocimiento debería construirse y, esto, aunado a la aberración de considerar al ego como si fuese un dato de los sentidos -icomo si el ego fuese uno más de los contenidos de una mentel- pronto lo condujo a abandonar la idea de que el yo pudiese ser objeto de conocimiento directo. ¿Qué curso tomaron después de su fracaso los pensamientos filosóficos de Russell sobre el ego y el problema de la autoreferencia?

3. En su artículo "On the Nature of Acquaintance", 11 Russell sostuvo que el yo sólo podía conocerse por descripción. Consideremos, nos dice Russell, al pronombre 'éste' como un nombre lógicamente propio, esto es, como una expresión que refiere directamente a un dato de los sentidos presente ante nuestra conciencia, sin necesidad de connotación alguna. Nada más fácil, entonces, que definir al pronombre 'yo' de la

11 Citado anteriormente. Véase la nota 9. 
siguiente manera: 'yo' significa 'el ego que tiene conocimiento directo de esto'.

Es aquí en donde Wittgenstein ataca. En su opinión Russell no ha entendido todas las implicaciones del argumento de Hume en el sentido de que el yo o ego no es un objeto de la experiencia. Olvidémonos por un momento de las dificultades que implica el pensar que el pronombre 'esto' refiere a lo dado y preguntemos a qué o a quién le es dado. "Al ego", responderíamos de inmediato, pero el problema es que, como dice Wittgenstein en el Tractatus, no hay manera de identificar al ego en la teoría de Russell salvo mediante la definición que nos propone y esto hace a la relación entre el ego y su experiencia una relación (de propiedad) necesaria. Decir esto implica, como veremos después, que el enunciado que afirma que un conjunto de objetos se presenta ante un ego particular es una verdad cognoscible $a$ priori.

Como advertí al iniciar este trabajo $(\$ 1)$, no desarrollaré las críticas de Wittgenstein sino hasta la siguiente sección. Por el momento me interesa hacer a un lado una objeción que sin mucho especular podría ocurrírsele a cualquier entusiasta de la "nueva" teoría de la referencia $(\$ 2)$.

Podría objetarse que la crítica de Wittgenstein consistente en señalar que si la teoría de Russell fuese verdadera la relación entre un ego y su experiencia sería una relación necesaria, descansa en una mera confusión. La teoría de Russell — nos diría este sujeto- podría fácilmente escapar a la conclusión a que he aludido en el párrafo anterior simplemente apelando a la noción de alcance (de una descripción). Pensemos a ' $\theta$ ' como abreviando la descripción 'el ego que tiene conocimiento directo de esto'. Si asumimos entonces que 'esto' refiere a un objeto de conocimiento directo, digamos un dato de los sentidos en el campo visual de $\theta$, la pregunta es: ¿se seguiría de aquí que $\theta$ tiene, necesariamente, conocimiento directo de esto? He dicho que, en la teoría de Russell, sólo podemos contestar afirmativamente a esta pregunta, pero el replicante que yo he imaginado me diría que esto no es asi, ya que depende de cómo tomemos esta última oración. Si la consideramos de una cierta manera si se sigue: basta dar a la descripción 'el ego que tiene conocimiento directo de esto' - abreviada por ' $\theta$ ' en nuestro ejemplo- menor alcance que al operador modal. Se seguiría entonces que no hay mundo posible en el cual $\theta$ no tenga conocimiento directo de esto. Pero tomada la oración de otra manera, esto no se sigue; en otras palabras, habría mundos posibles en los cuales $\theta$ no tendría conocimiento directo de esto. En este caso, deberíamos leer la oración de la siguiente manera: respecto del ego que tiene conocimiento directo de esto, es posible que él no tenga conocimiento directo de esto. 
Como podrán darse cuenta, el replicante ha basado toda su objeción en la distinción entre, por una parte, dar el significado de la palabra 'yo' y, por la otra, fijar su referencia - distinción la cual no parecería del todo descabellado pensar que se le hubiese ocurrido a Russell aunque, en honor a la verdad, Russell jamás hizo referencia a ella de manera explícita. Provistos de esta distinción —concluiría el replicantepodemos hacer del enunciado 'el ego que tiene conocimiento directo de esto tiene conocimiento directo de esto' un enunciado contingente y, por tanto, inmune a la crítica que Wittgenstein adelantó en el Tractatus, ya que, en el caso sujeto a discusión, dicho enunciado, siendo contingente, no podría conocerse a priori.

Pues bien, yo quisiera sostener que la distinción que Kripke ha hecho tan famosa entre dar el significado y fijar la referencia, no puede aplicarse en el contexto de la teoría de Russell. La razón es ésta: lo que Russell nos dice acerca de la categoría de nombres lógicamente propios, a saber, que toda expresión que pertenezca a esta categoría sólo puede referir a un objeto del cual el sujeto tenga conocimiento directo, no se aplica, por lo tanto, al pronombre 'esto' cuando éste refiere a un objeto material. $\mathrm{Y}$ es tan sólo en estos últimos casos que el mecanismo de fijar la referencia puede ponerse en práctica. He aquí el porqué de esta afirmación: el sentido que tiene distinguir entre dar el significado de una expresión y fijar su referencia estriba tan sólo en que nos permite distinguir las propiedades modales de oraciones que, o bien contienen expresiones cuyas respectivas referencias se fijan mediante descripciones definidas - lo cual, obviamente, da lugar a distinciones de alcance-, o bien contienen expresiones del tipo que Kripke llamó 'designadores rígidos', lo cual no es más que otra manera de decir que dichas expresiones no dan lugar a distinciones de alcance. Ahora bien, toda especulación sobre el status modal de oraciones en las que figuran expresiones que refieren a datos de los sentidos es enteramente ociosa, dado el carácter tan peculiar de los objetos referidos. Los datos de los sentidos sólo tienen una existencia momentánea, esto es, no persisten a través del tiempo y esto basta para remover la base sobre la cual pueden fundarse todas las especulaciones acerca de si un dato de los sentidos particular puede o no haber existido en otro mundo posible y, en caso de que esto fuese así, si se trata del mismo dato que el que existe en el mundo real. Es evidente, o al menos lo es para mí, que en el caso de los objetos materiales, sus propiedades y relaciones, sean éstas espacio-temporales $u$ otras, nos dan pie para todo este tipo de indagaciones, pero en el caso de los datos sensoriales no hay nada que nos sirva como base $y$, por tanto, no hay lugar para especulaciones sobre otros mundos po- 
sibles o, lo que es lo mismo, para la distinción entre dar el significado de una expresión y fijar su referencia.

La manera que he escogido de refutar la objeción que consideré arriba no es la única. También podríamos decir que no hay manera de fijar la referencia de una palabra mediante una 'ostensión mental' -ostensión que habría de tener un objeto privado en la mente del sujeto. Pero, en la teoría de Russell, esto es precisamente lo que se requiere. En su teoría, el simple atender a un objeto privado, el dato de los sentidos, se supone que es la manera como el pronombre 'esto' se aplica a su referente. Obviamente, cuando el acto de atender juega el papel al 'fijar la referencia' de 'esto' que ordinariamente juega la ostensión cuando el objeto de la referencia del hablante es un objeto material, la oración 'yo no estoy consciente (tengo conocimiento directo) de esto' carece de sentido. Pero la negación de un sinsentido es también un sinsentido, o bien, expresa una verdad necesaria pero, en todo caso, va en contra de lo exigido por el empirismo de Russell, a saber, que dicho enunciado sólo es cognoscible a posteriori.

4. Consideremos, ahora sí, la objeción de Wittgenstein a la teoría de Russell según la cual sólo puede conocerse el yo mediante descripción. Recordemos la objeción: en la teoría de Russell no hay manera de identificar al ego, a menos de que pensemos a la relación del ego y su propia experiencia como una relación necesaria. Por mi parte, pienso que esta objeción es realmente devastadora y la importancia de su análisis radica, creo, en que nos permite ver cómo si aceptamos la noción de lo dado -noción que se nos impone una vez aceptado el fundacionalismo epistemológico de Russell- nuestra posición se hace vulnerable a las objeciones kantianas que, en el caso a discusión, Wittgenstein parece haber recogido de Schopenhauer. ${ }^{12}$ Es importante notar que las objeciones kantianas se aplican, sea que tomemos como punto de referencia la experiencia del sujeto, su campo inmediato de conciencia o, alternativamente, el ego al cual se le presenta como poseedor de dicho campo $(\S 1)$. La teoría de Russell de que el yo es un objeto de conocimiento directo $(\S 2)$ ejemplifica este último caso, mientras que su teoría ue estamos examinando ahora, su teoría de que el yo sólo puede conocerse por descripción, ejemplifica el primero. Ambas teorías están condenadas al fracaso por lo que vienen a ser, en realidad, las mismas razones.

12 Esta conjetura resulta por demás plausible. Las metáforas que Wittgenstein emplea en su discusión sobre el solipsismo son idénticas a las que usa Schopenhauer. A este efecto. véase la obra de Schopenhauer The World as Will and Representation. Traducción al inglés de E. F. J. Payne, Dover, New York, 1966, especialmente, vol. I, p. 5 y vol. II, pp. 15, 278, 486, 491. 
Las criticas de Wittgenstein a esta segunda teoría del yo que Russell sostuvo aparecen en el contexto de su discusión del solipsismo en el Tractatus 5.6-5.641. Se trata de un pasaje enigmático, el cual, como varios comentadores han enfatizado, ${ }^{13}$ puede interpretarse de diversas maneras. Su discusión tiene un aspecto positivo y otro negativo. Si mi lectura es correcta, el aspecto negativo concierne enteramente el mostrar lo que para Wittgenstein era un error crucial en filosofía, a saber, argumentar sobre una base empírica a favor o en contra de una tesis metafísica. Un caso típico de este error es, según Wittgenstein, el argumento de Russell sobre la existencia de su yo. Russell conduce su argumento como si estuviese argumentando a favor de la existencia de un objeto, el cual, según nos revela una investigación empírica, no ha de ser objeto de conocimiento directo. Pero, de acuerdo a Wittgenstein, el solipsista tiene una tesis de gran importancia filosófica en mente, sólo que la presenta de manera incorrecta, ya que nos trata de decir lo que sólo se puede mostrar. Es este aspecto de su discusión el que resulta, en verdad, difícil de entender. Pasemos ahora al detalle de su argumentación.

Para poner en una perspectiva clara las críticas de Wittgenstein nos haría bien recordar la tesis russeliana de que toda palabra que seamos capaces de entender debe tener un significado que caiga dentro de nuestra propia experiencia. Dije en $\S 2$ que ésta es la base de aquella doctrina que algunos filósofos han denominado solipsismo lingüistico y hemos visto cómo, según Russell, una doctrina tal establece una restricción en nuestra manera de entender los significados. Pero, en opinión de Wittgenstein, Russell no ha cobrado aún conciencia de sus implicaciones filosóficas. Todo lo que necesitamos para refutar al solipsismo - pensaba Russell_ es argumentar que tenemos la suficiente evidencia científica para mostrar que existen determinadas cosas que no caen bajo nuestra experiencia inmediata. Por su parte, Wittgenstein piensa que esto no sería suficiente. Para él, ni la existencia de su yo ni tampoco la verdad que nos dice encontrar en el solipsismo pueden establecerse sobre una base empírica. Pero si esto ha de ser así, entonces, su teoría del lenguaje le impide decir cosa alguna sobre estos temas. De ahí, pues, su conclusión de que tales 'cosas' sólo se pueden mostrar.

En el pasaje 5.632-3 Wittgenstein nos dice: "El sujeto no pertenece al mundo: es, en su lugar, el límite del mundo. ¿En qué parte del mundo ha de encontrarse el sujeto metafísico? Se dirá que esto es exacta-

13 Por ejemplo, P. M. S. Hacker en Insight and Illusion, Oxford University Press, London, 1972, especialmente, capítulo 3; J. Hintikka "On Wittgenstein's 'Solipsism" " en Essays on Wittgenstein Tractatus (eds.) Beard \& Copi; D. Pears, "Wittgenstein's Treatment of Solipsism in the Tractatus", recopilado en su antologia Questions in the Philosophy of Mind., Ducworth, London, 1975, Cap. 11. 
mente como el caso del ojo y el campo visual. Pero, en realidad, uno no ve el ojo." Esto último va en contra de la teoría de Russell que considera al yo o ego como un objeto de conocimiento directo. El siguiente enunciado va en contra de su segunda teoría: "Y nada en el campo visual te permitirá inferir que lo ve un ojo." Considerada esta afirmación como una objeción en contra de Russell, el mensaje es bastante claro: Si hubiese algo en mi campo visual que me permitiese inferir que lo ve un ojo, entonces, debería ser posible también que dicha relación dejara de darse y esta situación es un imposible (\$2). En otras palabras, si se introduce un tipo de cosas como Russell pretendía introducir los egos, entonces, la correlación de egos con sus campos de objetos respectivos no puede establecerse empíricamente, pero esto era precisamente lo que exigía la teoría de Russell. "Esto está vinculado" - Wittgenstein continúa- "con el hecho de que ninguna parte de nuestra experiencia es a la vez a priori. Todo lo que vemos puede ser de otra manera. Todo lo que podemos describir podría ser distinto. No hay ningún orden $a$ priori de las cosas." 14

Es verdad que si yo tengo experiencia de un objeto o, como Russell diría, si yo tengo conocimiento directo de un objeto, la experiencia es $m i$ experiencia, es decir, soy yo quien tiene conocimiento directo de ese objeto. Pero si esto ha de ser más que una simple tautología, esto es, si el solipsismo que esta doctrina inspira ha de ser genuinamente restrictivo, mi yo o ego tendría que ser identificado de manera que no dependa de mi experiencia. Pero en la teoría de Russell esto es imposible. Su teoria de que el yo se conoce tan sólo por descripción requeria que, para poder usar la palabra 'yo', debería poseer alguna evidencia empírica de que hay una cosa que satisface la descripción 'el ego que tiene conocimiento directo de esto'. Pero, dada la teoría del significado de Russell, tal descripción se satisface necesariamente, es decir, la suposición de que no hay nada que la satisfaga carece de sentido. Es esta consecuencia de su teoría, pienso, lo que Wittgenstein tiene en mente en el pasaje que ahora comentamos. A no dudarlo, Wittgenstein tiene razón cuando escribe: "Todo lo que vemos puede ser de otra manera. Todo lo que podemos describir podría ser distinto." Pero si Russell estuviese en lo correcto, habria ciertos aspectos de nuestra experiencia respecto de los cuales esto no podría ser el caso.

La consecuencia importante de la crítica de Wittgenstein -la cual se basa en el hecho de que el ego no es un objeto de la experiencia- es que la aparente restricción que parecía imponernos el solipsismo lingüís-

14 Tractatus Logico-Philosophicus 5.6331-5.634. Traducción al inglés de D. Pears y B. McGuiness, Routledge and Kegan Paul, London, 1961. 
tico a que nos condujeron las teorías de Russell, es un mero show. Para que Russell evitara esta conclusión, debería decirnos cómo es posible identificar a un ego particular a través de los objetos de los cuales tiene conocimiento directo, pero ya hemos visto que, en la teoría de Russell, los egos se vinculan definicionalmente a los campos de objetos de conocimiento directo y esto hace de la verdad expresable por la oración 'Ego con conocimiento directo de esto' una verdad a priori y, por tanto, hace de su versión del solipsismo lingüistico una doctrina que no es genuinamente restrictiva. No niego que la versión de Wittgenstein también requiere de una previa identificación de un ego particular, pero la teoría del significado de Wittgenstein es una teoría completa y absolutamente general, la cual no depende para nada de cuestiones que derivan de la teoría del conocimiento. Es precisamente porque la ontología del Tractatus se deduce de una teoría tal - una teoría a la cual todo lenguaje posible habrá de conformarse-que su versión del solipsismo lingüístico es genuinamente trascendental.

La preocupación de Wittgenstein era establecer los límites del lenguaje y, para estos efectos, necesitaba, como he notado ya, una teoría del significado completa y absolutamente general. Wittgenstein llegó a pensar que había descubierto la esencia misma del lenguaje, lo cual le permitiría descomponer cualquier lenguaje en una serie de proposiciones elementales que servirían como la base para construir todas las proposiciones fácticas. La ambiciosa conclusión ontológica que se proponía derivar de esta teoría - conclusión que permite ver la discusión de Wittgenstein sobre el solipsismo como lo he propuesto- fue que estas proposiciones elementales reflejan la estructura de la realidad, una realidad compuesta de objetos simples que fijan el limite de las proposiciones susceptibles de entenderse. Es aquí donde puede verse a la filosofía del Tractatus como un ejemplo clásico de filosofía critica en el sentido kantiano: su ontología no es otra cosa que una metafísica del lenguaje construida en forma muy similar a la metafísica de la experiencia kantiana. Dicha ontología se deduce de una teoría del lenguaje, una teoría, repito, a la que todo lenguaje posible habría de conformarse: sobre la base de este supuesto, podria decirse que nada hay más firme que la ontología del Tractatus, ya que, supuestamente, ella misma incorpora las condiciones de posibilidad de todo lenguaje. La realidad proporciona, por así decirlo, el escenario sobre el cual el lenguaje puede llegar a existir y es por esto que, cuando viene a existir, necesariamente, habrá de reflejarla.

Así, el concepto de objeto en el Tractatus es un concepto formal precisamente en el sentido de Kant. Según Wittgenstein, cada uno de estos objetos se encuentra en un "espacio de posibles situaciones objetivas" y 
toda combinación posible de objetos es necesariamente posible. Los objetos visuales, los colores, por ejemplo, se encuentran en un espacio de color; las notas musicales en un espacio de sonido. Un objeto espacial no puede estar fuera del espacio, ni tampoco una nota puede tener un color, un olor, o un sabor. La sustancia del mundo determina una forma (Tractatus, 2.0231), es decir, un rango de posibilidades de combinación. Pero ¿cuál es la naturaleza de esta determinación? ¿Qué tipo de necesidad impide que un color pueda concatenarse con una nota musical? La respuesta es, obviamente, que todas estas preguntas carecen de sentido ya que dichas preguntas violan los límites del lenguaje. Las únicas verdades necesarias, para el Wittgenstein del Tractatus, son las verdades de la lógica y éstas pueden ser captadas por el lenguaje y, con su ayuda, pueden mostrarse los límites del lenguaje y los límites del lenguaje son los límites del mundo. No obstante, no puede ser del todo correcto afirmar que toda la necesidad es necesidad lógica: a diferencia de la necesidad lógica, la necesidad metafísica no puede ser atrapada por el lenguaje y, por tanto, no podrían darse proposiciones metafísicas en el Tractatus que describan las restricciones que afectan a las posibilidades de combinaciones de objetos. Dichas restricciones emergen en el lenguaje tan sólo como reglas de formación cuyo propósito es reflejar la sintaxis lógica del lenguaje, determinando así el uso de una variable y, de esta manera, su rango de valores posibles. Ésta es una especie de super-ffsica de los objetos tendiente a determinar la forma del mundo.

La concepción wittgensteiniana de las proposiciones elementales como proposiciones lógicamente independientes entre sí y susceptibles de confrontarse directamente con la realidad para determinar su verdad o falsedad implicaba ya su doctrina de los objetos simples como formando la sustancia del mundo, los cuales fijan el límite de las proposiciones susceptibles de entenderse. El vínculo con la versión del solipsismo lingüístico por el que pugna Wittgenstein se establece así: al delimitar el rango de todas las proposiciones que pueden entenderse mediante el conjunto de objetos que forman la "sustancia del mundo" quedarían fijados a la vez los límites de $m i$ lenguaje. Esto es por la sencilla razón de que $m i$ lenguaje es tan sólo un subconjunto del conjunto de proposiciones susceptibles de entenderse, es decir, del conjunto de proposiciones con sentido; y, para redondear el tema, según Wittgenstein, los límites de mi lenguaje son los límites de mi mundo. Ahora bien, si preguntamos cómo han de especificarse los objetos que constituyen la "sustancia del mundo", hay una respuesta que debemos rechazar de inmediato. Sería inútil contestar a esta pregunta diciendo que esos objetos son los objetos de $m i$ mundo, ya que, en el Tractatus, el yo del solipsista no está en el mundo - -es su límite. 
En 5.5561 Wittgenstein afirma que la "realidad empírica está limitada por la totalidad de objetos" y esto parecería sugerir que el que haya tales o cuales objetos en el mundo es una cuestión empírica, pero pensar esto sería un error craso, ya que el rango de objetos fija el límite de todas las proposiciones entendibles de manera que es imposible decir, cumpliendo a la vez con los cánones de la lógica: "El mundo tiene esto y eso pero no aquello" (5.61). Siguiendo una sugerencia de J. Hintikka, ${ }^{15}$ David Pears nos propone ${ }^{16}$ la analogía de una caja de cerillos de la cual podemos decir que contiene este cerillo y este otro pero no aquél. Podemos hacer esta afirmación porque los límites de la caja no los fija su contenido. Pero el mundo en el Tractatus es una cuestión distinta, ya que su 'sustancia' fija a la vez el límite de lo que puede entenderse, el límite de lo que tiene sentido y, así, fija el límite del mundo mismo: "La lógica permea (pervades) al mundo: sus límites son también los límites del mundo" (5.61). Por tanto, que el mundo tenga ciertos límites, es decir, que haya tales o cuales objetos, es algo que sólo se puede mostrar.

Esta tesis - central en la argumentación de Wittgenstein- se aplica no sólo a la totalidad de objetos y al mundo en toda su extensión sino, además, a la relación entre mis objetos y $m i$ mundo, así como también a la relación entre mis objetos y el único lenguaje que yo entiendo y a la relación entre la totalidad de objetos y el lenguaje en general. Esto explica por qué la discusión de Wittgenstein sobre el solipsismo se abre con el comentario: "Los límites de mi lenguaje son los límites de mi mundo", 17 comentario el cual, según el propio Wittgenstein, nos da la clave del problema respecto a la verdad que se encuentra en el solipsismo. La clave para entender este problema es reconocer el hecho de que ambos, mi mundo y el mundo, son como 'recipientes' cuyos límites los fija su contenido y de ahí que, sean éstos cuales fueren, sólo se pueden mostrar.

Estamos ahora en condiciones, espero, de entender lo que Wittgenstein considera como el gran insight del solipsista. Su idea brillante es, según Wittgenstein, que los límites del mundo y del lenguaje se fijan por un cierto rango de objetos. El problema es que el solipsista echa por la borda su brillante idea cuando intenta ponerla en términos que darían como resultado una proposición contingente, ya que esto es un imposible. ¿Cómo podemos entender, entonces, lo que nos dice el solipsista al afirmar que el mundo es su mundo una vez que hemos aceptado lo inútil de considerar a su ego como un punto de referencia?

15 Ver la nota 13.

16 En su artículo citado en la nota 13, p. 287.

17 Tractatus, 5.6. 
"El yo del solipsismo - Wittgenstein escribió- viene a ser un punto sin extensión." 18 Ahora bien, si esto es correcto hay tan sólo una manera de interpretar o de entender la afirmación del solipsista de que el mundo es su mundo, y ésta consiste en privar de toda fuerza referencial a su uso del pronombre 'yo' o de sus derivados. ${ }^{19} \mathrm{La}$ palabra 'ego' no refiere, por tanto, a un objeto identificable y esto es lo mismo que decir que no es un nombre en absoluto. Si pretendiésemos escribir la propuesta del solipsista en el modo material diríamos que se trata de una tesis acerca del fenómeno de la subjetividad, pero entonces, ¿qué es lo que queda de las restricciones que parecía imponernos el solipsismo? 'Nada' —contestaría Wittgenstein y, en efecto, esto es lo que nos dice: "Cuando las implicaciones del solipsismo se sigan estrictamente se verá que coincide con el realismo puro" (5.634). Al recapitular sus puntos de vista sobre el ego y el solipsismo en los Notebooks, Wittgenstein escribe: "Éste es el camino que he recorrido: el idealismo escoge a los hombres de entre el mundo; el solipsismo me escoge a mi nada más" y ambas doctrinas son falsas. "Pero" — continúa Wittgenstein— "habiendo llegado al final del camino caigo en la cuenta que yo también pertenezco al mundo $y$, así, por una parte, nada dejamos fuera", es decir, no hay ningún ego o sujeto metafísico, "y, por la otra, como algo único queda el mundo. Es así como el idealismo nos lleva al realismo si lo pensamos a fondo." 20

5. El argumento de Hume de que el yo no es un objeto de la experiencia demolió la teoría de Russell de que el yo sólo puede conocerse directamente, pero ese argumento no es igualmente efectivo en contra de la concepción que Wittgenstein tiene del sujeto metafísico, ya que él no lo considera como algo en el mundo sino, en su lugar, como su límite. Esto hace del solipsismo de Wittgenstein algo genuinamente trascendental. Dada la influencia de Schopenhauer en este período de su filosofía, la existencia del yo la exigían sus doctrinas de la voluntad, así como también sus doctrinas éticas sobre el bien y el mal. En los Notebooks nos dice: "Bien y mal entran sólo a través del sujeto. $Y$ el sujeto no es parte del mundo sino su límite" y, más adelante: "Sería posible decir (à la Schopenhauer): No es el mundo como idea el que es bueno o malo, sino el sujeto encarnado en su voluntad." ${ }^{21}$ No voy a analizar aquí nin-

18 Notebooks, 2.9.16; Tractatus 5.64.

19 Esta propuesta la ha hecho suya E. Anscombe en su libro An Introduction to Wittgenstein's Tractatus, Hutchinson University Library, London, 1963, p. 168. En el mismo sentido véase D. Pears, ibid., p. 289.

20 Notebooks 1914-1916, 15 de octubre de 1916; ed. G. H. von Wright y E. Anscombe, con traducción inglesa a cargo de esta última, Basil Blackwell, Oxford, 1969. 21 Ibid., p. 79. 
guna de estas tesis sino, en el espacio restante, intentaré mostrar que en la tesis de Wittgenstein que le reconoce un insight profundo al solipsista es donde encontramos el origen de la tesis que vino a sostener años después sobre el uso no referencial del pronombre.

Ahora bien, es obvio que, cuando un filósofo niega que el pronombre 'yo' sea una expresión referencial, no por eso se ve comprometido a negar la regla "Si X hace una aserción con el pronombre 'yo' como sujeto, su aserción será verdadera si y sólo si el contenido de su aserción es verdadero de X". En esa medida los hechos no están sujetos a disputa. Lo que se pretende con esa tesis es explicar el fenómeno de la auto-conciencia o, para decir lo mismo en el modo formal, dicha tesis pretende ofrecernos una explicación de los enunciados en primera persona. El reconocimiento de Wittgenstein de que hay una verdad en el solipsismo deberá entonces manifestarse en que el análisis de la oración "Yo tengo la experiencia de $\varnothing$ ' (en donde ' $\varnothing$ ' es una variable cuyo rango son los predicados mentales o psicológicos) difiere radicalmente del análisis de oraciones como "A tiene la experiencia de $\emptyset$ ", en donde ' $A$ ' refiere a algún tercero. Wittgenstein pensó que, en el primer caso, se hacía referencia a la experiencia, por ejemplo, al dolor, mientras que, en el segundo, sólo se hacía referencia a la conducta del sujeto mediante la cual manifestaba ese dolor. Pero la experiencia a la que se hacía referencia en el primer caso no podía ser construida como una relación entre sujeto y objeto, ya que esto la haría blanco de las críticas de Hume que hemos visto que Wittgenstein acepta. Pero si los análisis respectivos de cada oración no difieren entre sí porque en un caso debe introducirse un ego que no figura en el otro, ¿cómo explicar entonces la diferencia? En otras palabras, ¿cómo ha de manifestarse la verdad que encierra el solipsismo? A mi entender, sólo de una manera: asumiendo que el uso del pronombre 'yo' no es un uso referencial, mientras que nadie duda que la expresión 'A' que sirve como sujeto (gramatical y lógico) a la segunda oración refiere a una persona.

En 1929 Wittgenstein rechazó la teoría semántica que había adelantado en el Tractatus y se embarcó en la tarea de construir una nueva teoría del significado con presuposiciones e implicaciones muy diversas. Antes de que esta nueva teoría semántica viese la luz, Wittgenstein pasó por una etapa de verificacionismo extremo, durante la cual sostuvo que los enunciados de primera persona, en tiempo presente y en los que se hacía referencia a la experiencia eran paradigmas de proposiciones, ya que todos ellos podían ser directa y concluyentemente verificados. Durante esa época de su filosofía el tema del solipsismo no figura de manera prominente en sus discusiones, pero la tesis del status no referencial del pronombre 'yo' se propone de manera explícita y se hace de una 
manera tal que nos recuerda las luchas previas de Wittgenstein con esa doctrina. La forma general de las proposiciones que Wittgenstein consideraba como paradigmas era "Yo siento ..." o "Yo tengo ..." y, en todos estos casos en los que el espacio en blanco lo llena un predicado mentalista, Wittgenstein nos dice que el pronombre 'yo' no denota un poseedor. En sus conferencias de 1930-3 enfatiza que "ningún ojo físico es necesario para la experiencia perceptual ... ningún ego debe postularse en el proceso de pensamiento o la experiencia de dolor". Wittgenstein consideraba a la res cogitans cartesiana como una mera ilusión y se ha dicho ${ }^{22}$ que se refirió con aprobación al dictum de Lichtenberg de que, en lugar de decir 'Yo pienso', Descartes debió decir 'Hay un pensamiento'.

Wittgenstein pronto abandonó esta etapa de verificacionismo extremo y a las proposiciones que antes consideró como paradigmas por ser directamente verificables ahora las consideraba como proposiciones que no daban lugar al problema de la verificación. Tener un dolor es una experiencia primaria, directa, y, por esta razón, Wittgenstein sostuvo que no tenía sentido preguntar cómo es que el enunciado 'Yo tengo un dolor' puede ser verificado. La pregunta ¿y cómo sabes tú que tienes un dolor? Wittgenstein la consideró como un mero sinsentido. De aquí se desprenderían posteriormente sus doctrinas del status no-cognoscitivo de los testimonios de primera persona, así como también su doctrina de los dos usos del pronombre 'yo' - lo que Wittgenstein llama "el uso como objeto" y "el uso como sujeto". ${ }^{23}$ Ambas doctrinas las pensó Wittgenstein como parte esencial de su campaña en contra del dualismo cartesiano y de la concepción de la auto-conciencia que presupone. Ambas doctrinas, sin embargo, son falsas. Finalizaré este trabajo diciendo algunas palabras únicamente sobre la segunda de estas doctrinas.

Wittgenstein se impresionó por algunas perplejidades que la aserción de oraciones como "yo tengo un dolor" traen consigo. Por una parte, notó que al decir "Yo siento dolor" no es necesario identificar al sujeto $y$, por la otra, reconoció que dudar de la aplicabilidad del predicado psicológico a uno mismo carece de sentido. Son estas dos caracteristicas, obviamente relacionadas entre sí, las que llevan a Wittgenstein a distinguir casos como el de la oración "Yo tengo un dolor" y "Yo tengo un lunar en la espalda". Sólo en estos últimos casos el pronombre de la primera persona desempeñaba, según Wittgenstein, una función referencial. Dicho pronombre se consideraba entonces como una expresión ambigua: su significado variaba según el uso que se le diese - sea un uso como

22 Véase "Wittgenstein's Lectures in 1930-33" en G. E. Moore, Philosophical Papers, Allen \& Unwin, 1959.

23 The Blue and Brown Books, Blackwell, Oxford, 1958, p. 67. 
sujeto o bien sea como objeto. Al usarlo como sujeto, el pronombre no tenía fuerza referencial, debida cuenta que, como afirma Wittgenstein, "en estos casos uno no escoge a una persona (que sirva como referente) dentro de todo un grupo de gente". Esto era lo que explicaba por qué cuando digo "Yo tengo un dolor" no surge la posibilidad de cometer un error por lo que toca a la identidad de la persona que sufre el dolor. Wittgenstein está aquí llamando nuestra atención a ese hecho crucial de nuestra experiencia, a saber, que en la auto-adscripción de pensamientos y creencias no es necesario emplear ningún criterio de identidad para reconocer o identificar al sujeto del pensamiento o creencia. Es por esto que, en la auto-adscripción de experiencias, uno es inmune al error a través de una falsa identificación con respecto al pronombre de la primera persona. ${ }^{24}$ Pero la manera que Wittgenstein escoge de explicar este fenómeno - mediante la negación de toda fuerza referencial al pronombre 'yo' en algunos de sus usos- carece, en mi opinión, de verdadero fundamento. A no ser que una expresión sea ambigua, siempre debería hacer la misma contribución semántica a toda oración en la que figura. Si Wittgenstein estuviese en lo correcto esto no sería verdad del pronombre de la primera persona $y$, aunque estoy consciente que decir esto no constituye sin más una reductio ad absurdum de su teoría, me parece que cualquier otro análisis que explique los hechos sin implicar esta conclusión debe preferirse.

24 En este sentido sería útil la lectura del artículo de S. Shoemaker 'Self-Reference and Self-Awareness', The Journal of Philosophy, (1968). 